\title{
Publisher Correction: A glycolytic shift in Schwann cells supports injured axons
}

Elisabetta Babetto ${ }^{D}$, Keit Men Wong and Bogdan Beirowski ${ }^{0}$

Correction to: Nature Neuroscience https://doi.org/10.1038/s41593-020-0689-4, published online 17 August 2020.

In the version of this article initially published, contrast levels in some panels in Fig. 5d-g, 7e and 8b,c,h incorrectly appeared lower relative to other panels; and in the first paragraph of the Methods section "Culture of primary neurons" the catalog number for penicillin-streptomycin should have been 1514012. The errors have been corrected in the PDF and HTML versions of this article.

Original

d
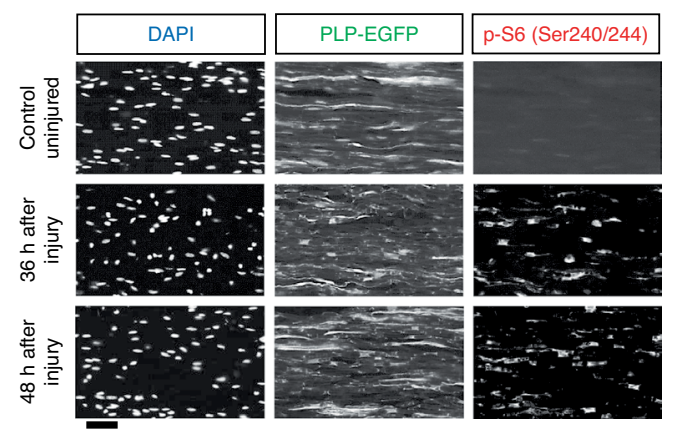

$36 \mathrm{~h}$ after injury

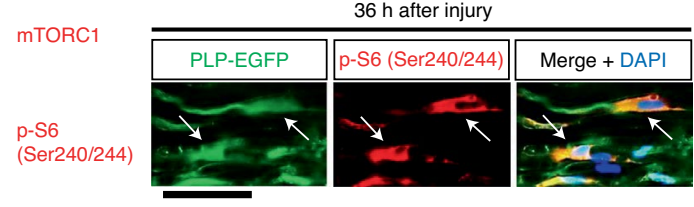

f
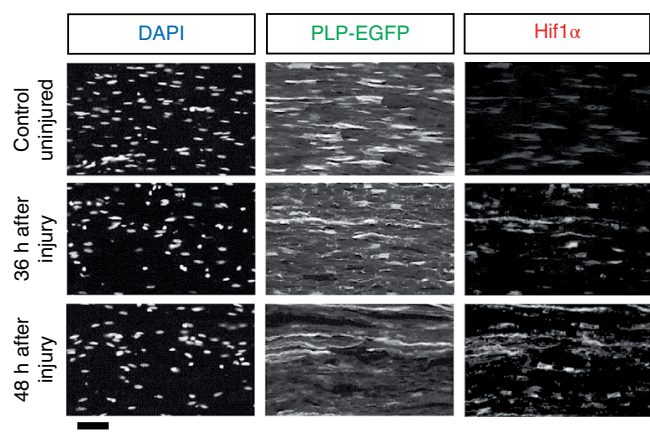

$36 \mathrm{~h}$ after injury

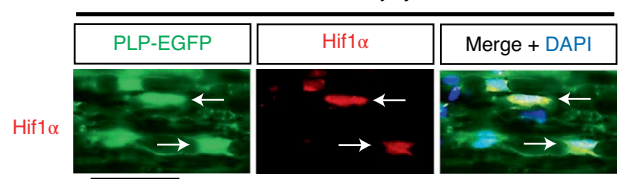

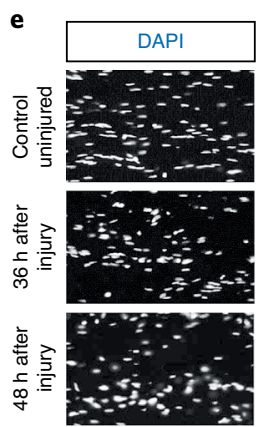
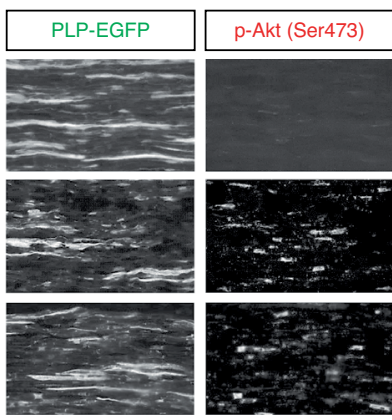

$36 \mathrm{~h}$ after injury

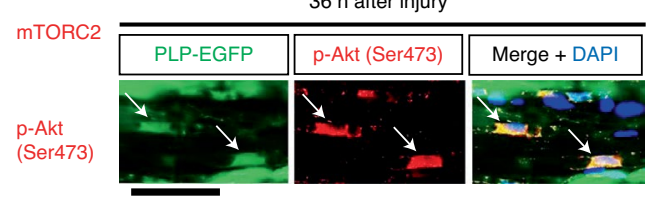

g
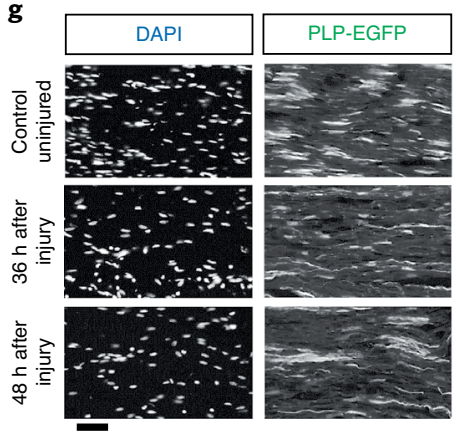

$36 \mathrm{~h}$ after injury
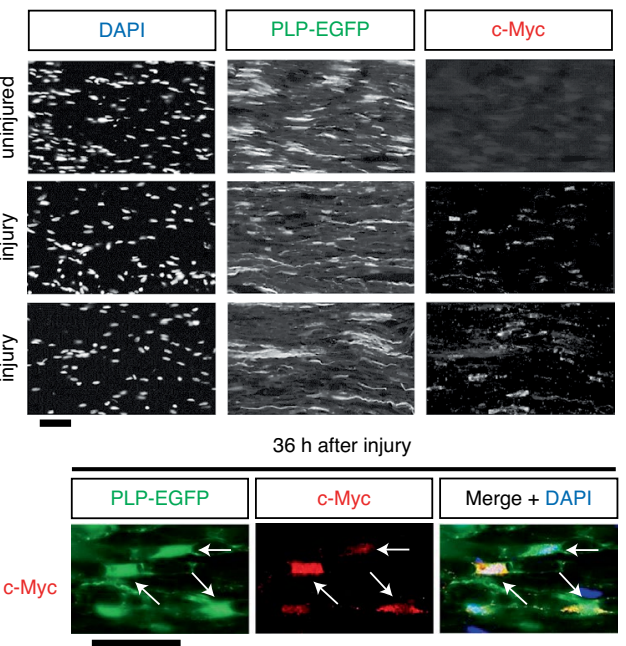


\section{Corrected}

d
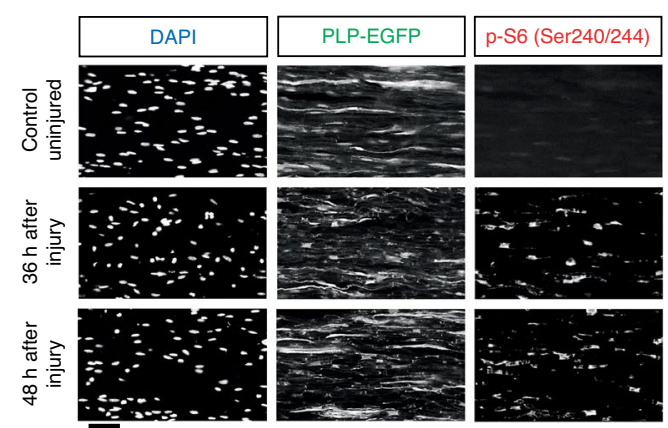

$36 \mathrm{~h}$ after injury

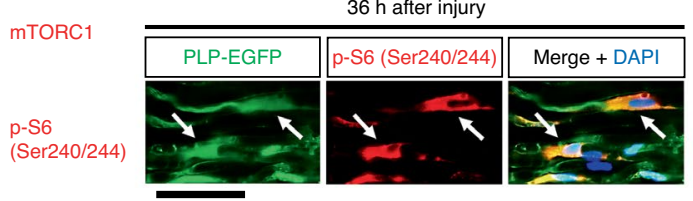

f

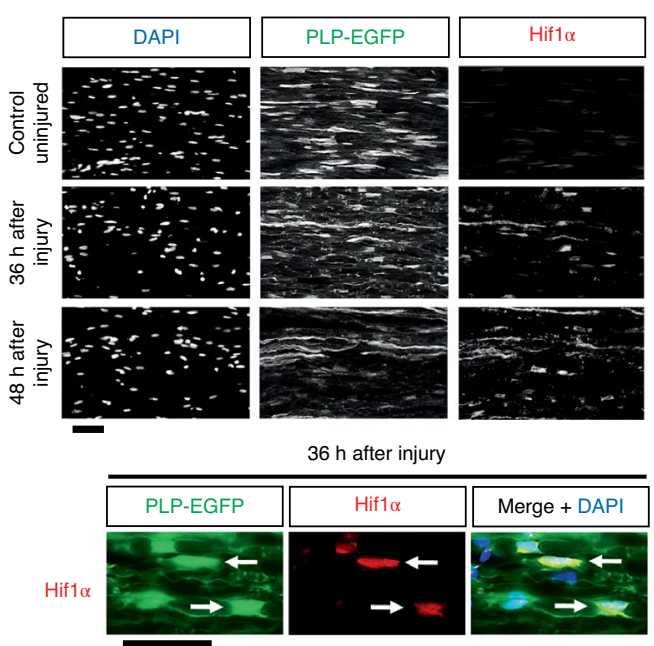

Fig. 5 | Original and Corrected.
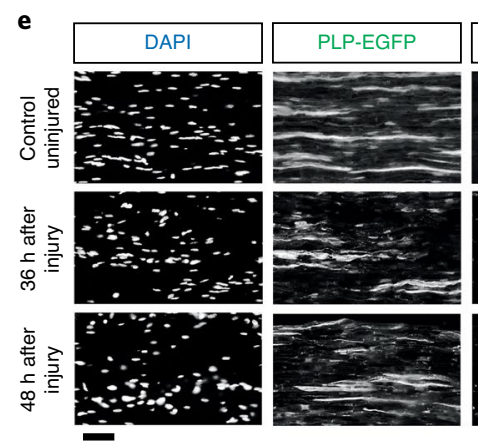

p-Akt (Ser473)
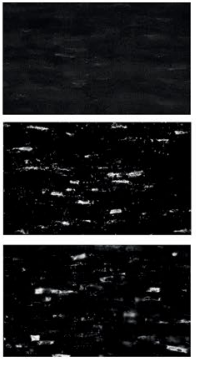

$36 \mathrm{~h}$ after injury

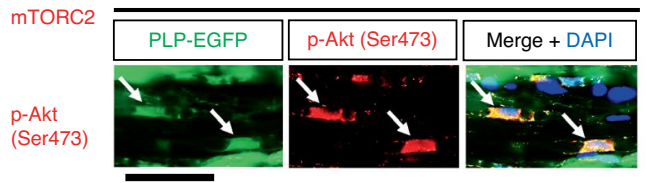

g
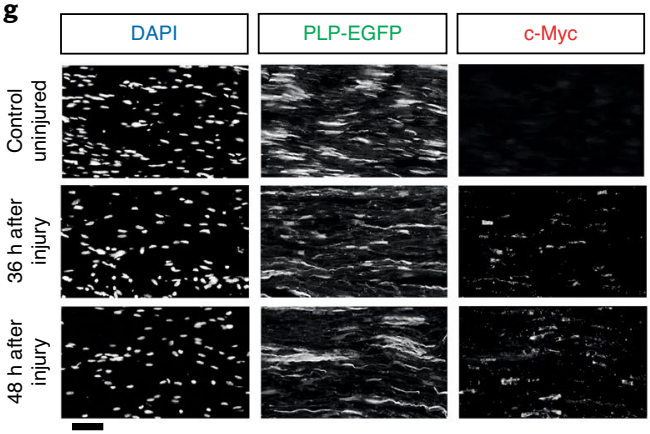

$36 \mathrm{~h}$ after injury

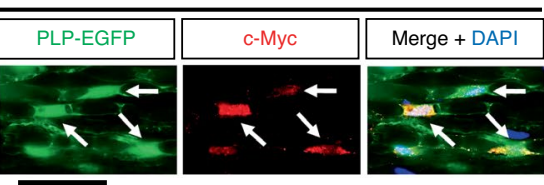

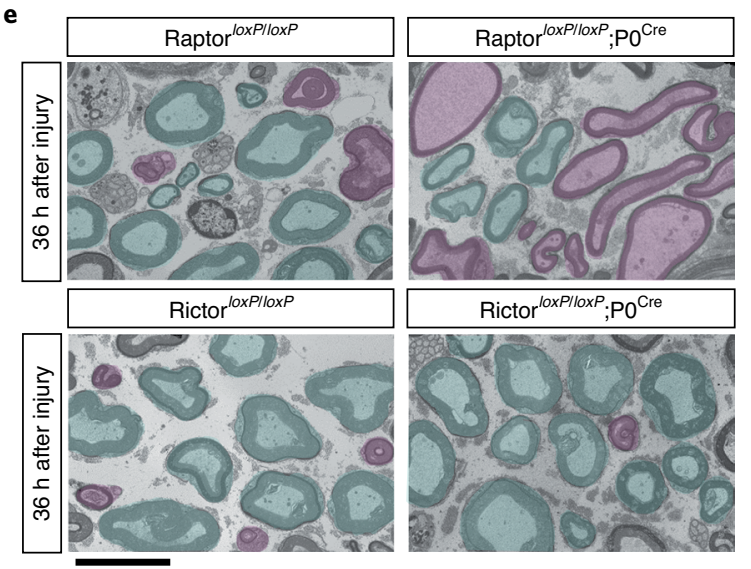

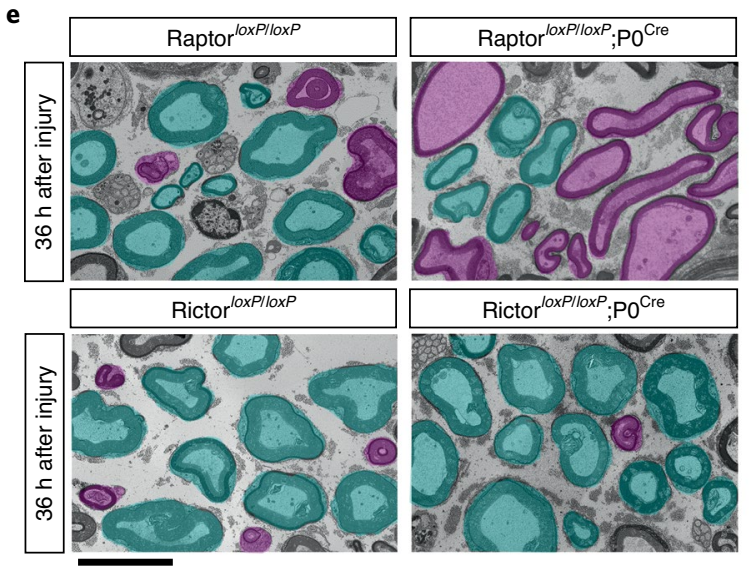

Fig. 7 | Original and Corrected. 
b

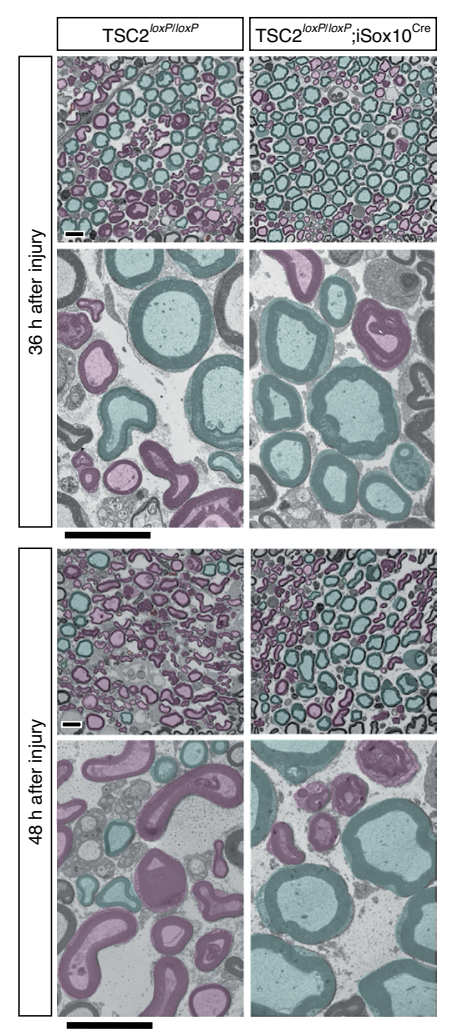

c

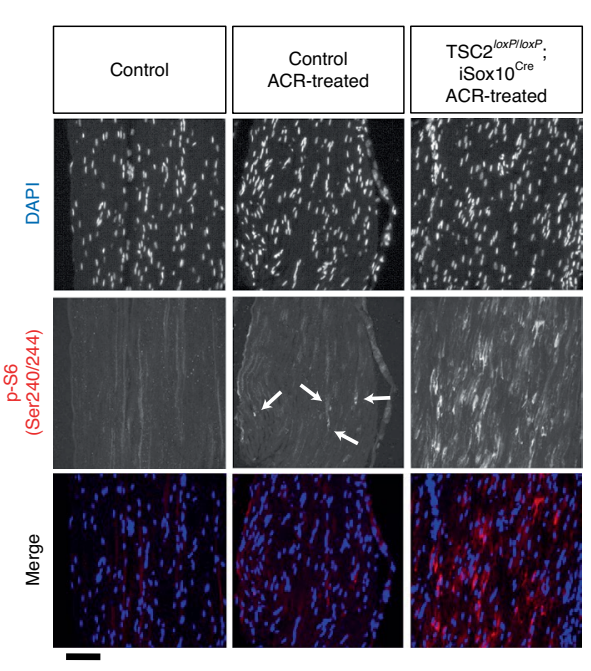

Corrected

b

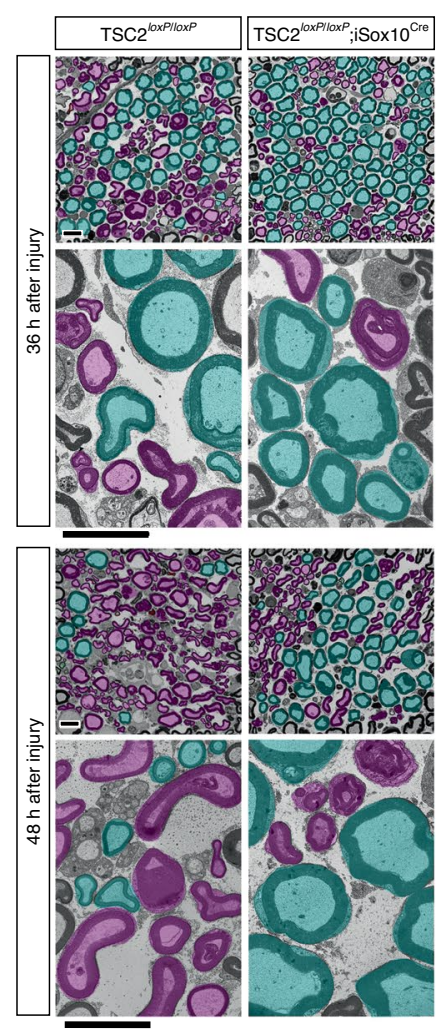

c

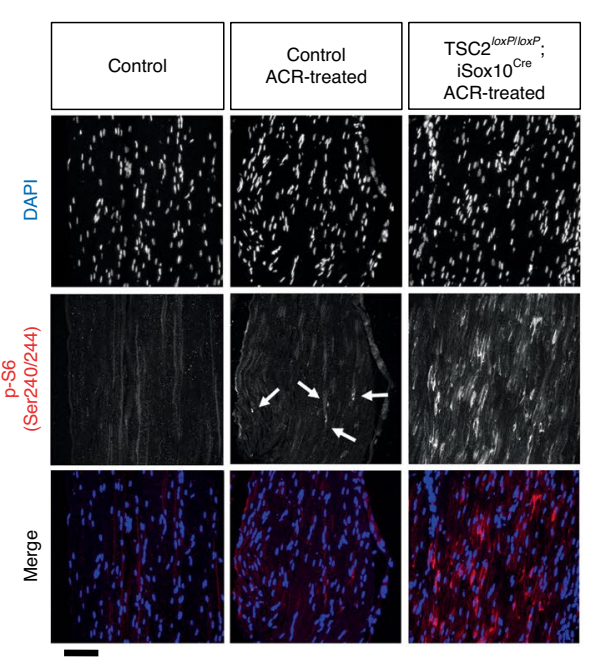

Original

h

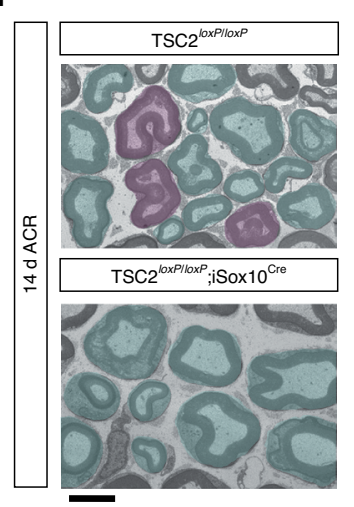

h

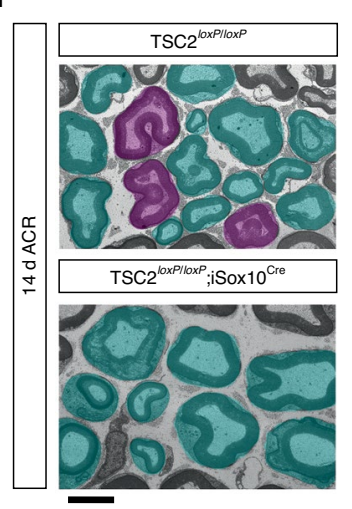

Fig. 8 | Original and Corrected. 


\section{NATURE NEUROSCIENCE}

Published online: 16 October 2020

https://doi.org/10.1038/s41593-020-00731-2

(๑) The Author(s), under exclusive licence to Springer Nature America, Inc. 2020

\section{Publisher Correction: Schwann cell energy to die for}

Amelia Trimarco (1) and Carla Taveggia (1)

Correction to: Nature Neuroscience https://doi.org/10.1038/s41593-020-00707-2, published online 8 September 2020.

In the version of this article initially published, an incorrect DOI was provided for ref. 6. The link should lead readers to https://doi.org/10.1038/s41593-020-0689-4. The error has been corrected in the PDF and HTML versions of this article.

Published online: 12 November 2020

https://doi.org/10.1038/s41593-020-00755-8

(C) Springer Nature America, Inc. 2020 